\title{
The Human Dimension of AIDS in Cuba: Jorge Pérez MD MS \\ Director, Pedro Kourí Tropical Medicine Institute
}

\author{
By Gail Reed MS
}

Except for the people living with the disease, no others have so immersed themselves in Cuba's world of HIV/ AIDS as Dr Jorge Pérez. It is a world of Cuban returnees from Angola's war against apartheid South Africa, gay and bisexual men, housewives, transactional sex workers, rebellious teenagers, and infected surgeons and scientists-a cultural kaleidoscope reflecting all the faces of AIDS. To more than one international author, he is simply "Cuba's AIDS doctor." Speaking to his patients at the Pedro Kourí Tropical Medicine Institute in Havana, it is easy to see why, but also to appreciate the courage, compassion, and persistent search for new knowledge that characterize the Institute's staff as a whole. Dr Pérez's story-now told in two books based on his diaries-is not his alone.

MEDICC Review held two interview sessions with Jorge Pérez just days apart at the beginning of April: one before and one after his designation as the new Director of the Tropical Medicine Institute, where he previously served as Deputy Director and Chief of Hospital Services. More than strictly medical matters, the conversation turned

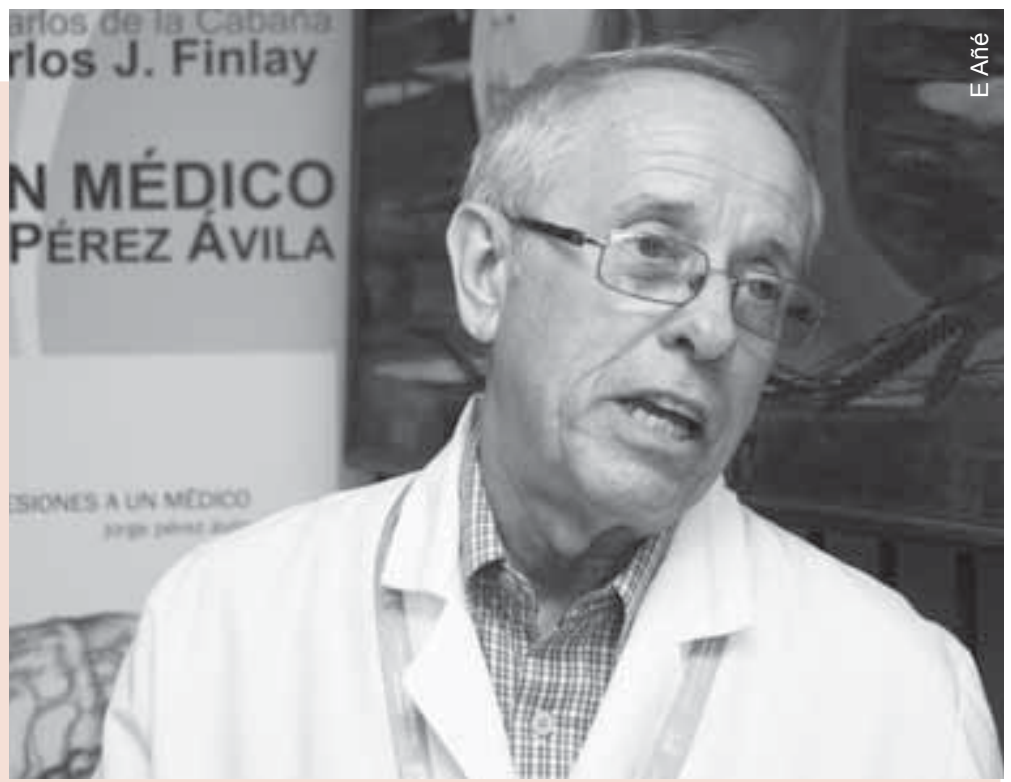

to the human dimension of HIVIAIDS, the depth to which it has touched many directly and affected Cuban society as a whole, and the challenges ahead for Cuba's flagship institution for research and treatment of infectious diseases.

\section{MEDICC Review: Why did you decide to write your first book?}

Jorge Pérez: It was the suffering of my patients, who faced such a different and difficult disease. I've been a doctor since 1973, but HIVIAIDS was a new world for me too, a complicated world of truths and also of lies. Of lives lived in the open and in the shadows. I began to see how important my patients' stories were. How they lived and suffered, their vulnerability and the different paths that brought them to me as their physician.

For 12 years, I directed the Santiago de las Vegas AIDS Sanatorium in Havana [where all HIVIAIDS patients were required to live until 1993, eds]. The place always had a certain mystiquepeople had no idea what it was like, what life there was like. And I realized I was an exceptional witness, and also part of a story that needed to be told.

In addition, I wanted the book to reflect what we have accomplished in HIVIAIDS, for which I think we should be proud. [In the 1990s], when the country was at its worst economically and people were living on almost nothing, our patients had a 5400-calorie diet. We worked with them, studied their cases, and scoured the literature on the disease.

I kept a diary, not every day, but whenever something moved me-which was often. And I still keep it today. It's where I let my feelings out. And so, the first book was mainly about the patients in the sanatorium-where I spent hours and hours hearing their stories.

At the same time, AIDS: Confessions to a Doctor wasn't just my own: it was an effort by many people-I discussed whole chapters with my patients, consulted relatives of those who were already gone. It's a book by all of us.

MEDICC Review: Obligatory sanatorial care was undoubtedly the most controversial part of Cuba's early HIVIAIDS strategy. But your tenure as director there brought changes that patients still talk about today.

Jorge Pérez: I learned so much there. The first thing I did was listen, try to understand what HIVIAIDS meant to all these people living there. The doctor-patient relationship, and particularly respect, is fundamental to any successful treatment, so first you have to try to understand. But it was tough, because at the same time, you're immersing yourself in people's intimacies and in very different experiences and cultures.

In the process of trying to transform my patients' lives, I found I also changed, and my convictions became stronger. We started a newsletter, involved patients in working in various departments at the sanatorium; at one point, we had 44 organic gardens going and we were raising chickens, rabbits and 250 pigs to supplement the already-reinforced diet. 
All this was a radical change, and it was the late 80 s. One day a patient told me: "Perestroika's come to the sanatorium!" I answered, "No, it hasn't. This is 'Perez's troika', and there's a big difference!" In any case, the point was to transform the sanatorium from a closed, isolated institution into a public place where people could come, could visit. We worked to achieve respect among vastly different kinds of patients, to make living together easier and help resolve their conflicts. We tried to humanize the conditions with one principle: patients come first.

Yet, in the early days, there was a lot of ignorance. We provided care at the sanatorium, but patients were separated from their families: they became strangers to their own families. In 1989-90, we started a program for patients to go home on weekends with a family member who would guarantee their responsibility and return.

Policy-wise, we worked to demonstrate that HIVIAIDS was one more health problem, not some mysterious illness-and to provide the evidence that this was so, that we would have to learn to live with HIVIAIDS in our communities. In this respect, the patients themselves began to contribute to change: they argued that their illness shouldn't confine them to the sanatorium. And that was a point of view that deserved serious consideration, surely.

Then came the AIDS Prevention Group, GPSIDA, and a stronger emphasis on prevention messages and measures. We began sending health promoters - the patients themselves-to schools and universities to talk about prevention. And we established a commission made up of psychologists, family doctors, epidemiologists, social workers, etc. to analyze each case. People began leaving the sanatorium for longer periods; couples would guarantee each other's responsible behavior, and so on.

Finally we moved towards an ambulatory care system, where people returned home. We were surprised to see that, at first, they didn't want to: they were afraid of the change. We had to begin to train family doctors, who could ease patients' re-entry into their communities. The STI-HIVIAIDS Prevention Center was established, and helped in this respect. It later began other programs including the anonymous hotline and counseling services, extending these beyond Havana.

\section{MEDICC Review: Your first book was a revelation to many people...even shocking to some.}

Jorge Pérez: Yes, because it spoke forthrightly about HIVIAIDS and related problems, which have been a huge challenge for our society.

Recently Cuban film director Gerardo Chijona released his feature Boleto al Paraiso (Ticket to Paradise) based on one of the book's chapters, which tells the story of a group of troubled, alienated and reckless teens who were living a sort of nomadic life, and purposefully sexually infected themselves with HIV to 'live better' in the sanatorium. The story is tragic, especially since they didn't actually realize they were facing death. Although the situation has changed a lot since then, the film itself has helped focus attention on the dangers of adventurous, unprotected sex, and the immaturity that can lead to such tragic decisions.

Today, Cuban society is better prepared to deal with HIVIAIDS: people, including health professionals, are less fearful when they understand something better. We've worked hard to achieve more understanding of the disease, more respect for the people infected. In this sense, health workers have been very receptive. People living with HIV continue in their jobs. More women with HIV are deciding to have children-they have that right, and also the responsibility to take care of themselves and protect their unborn child. Thus far, 399 seropositive women have given birth (some twice, and 10 twin pairs) for a total of 431 children born to them. Through December 2010 , only 37 children have been infected through vertical transmission.

In the beginning, we detected the infection primarily in heterosexual men, so we began looking for the virus in that population; later, we found it among homosexual men. Today the majority of people infected are men and among those, men who have sex with men. In this regard, we've made strides against homophobia in the general public, by defending the right to health and the need to care for all HIV-positive people.

But the picture isn't entirely rosy. There is less stigma associated with the illness, but it's not gone. Homophobia is still a factor in lack of family support for some of our gay patients. And while we've made progress, Cuban machismo takes more effort to overcome.

\section{MEDICC Review: How would you describe where the Nation- al HIVIAIDS Program is now?}

Jorge Pérez: So much has changed since I entered the world of AIDS 25 years ago: then it had a different connotation, fueled by ignorance. Our approach was different than in other countries, and the results have been satisfactory in many ways. Above all, we have managed to achieve comprehensive care for our patients, and universal anti-retroviral coverage, thanks to domestic production of ARVs. Over $87 \%$ of our HIVIAIDS patients are still alive.

Yet, HIVIAIDS is occurring in a poor country, where treatment is free to patients but extremely expensive for the health systemand where cases requiring treatment are increasing. Right now we have a rate of $0.1 \%$ among 15 to 49 -year-olds; but each year, incidence increases.

We have to be able to reach a plateau, by avoiding that slow but steady incidence increase-and finally to decrease incidence.

The ambulatory program, and further decentralization of services, are tremendous steps forward but present their own challenges. For example, some patients who decided to stay in the sanatorium, who work there as well, were already very sick with AIDS when they started ART. So they immediately and clearly saw the huge changes the ARVs made in their quality of life and in their prognosis as well.

But the outpatient group that is just now beginning ART looks at things differently: they were never so sick, they haven't suffered as much, and they know their lives are less in danger. Their illness is recently detected; they have treatment at their fingertips, even for opportunistic infections. That's the achievement.

But then because they don't feel as threatened, they don't take as much care, they don't see the specter of death in the mirror. Adherence to therapy becomes a bigger challenge, and others even refuse treatment...they close themselves off to the world, and they die. 


\section{Interview}

This means risk perception is a big problem, paradoxically because treatment exists, because infection is no longer synonymous with death. Our challenge is to make sure that everyone gets the message that the infection is very serious-and that requires targeting our messages better to specific groups, and reaching out to them.

We also have the specific problems of dysfunctional families. Of sex as sport-and unprotected at that. We see material and other interests perverting values that understand sexuality as something more. Something deeper.

In the process of decentralizing services, making them available in the community, we have to pay special attention to patient confidentiality. But at the same time, we have to figure out how, within ethical principles, to remove the stigma and make HIV infection more "natural." This also leads to another ethical dilemma: there are people who don't want anyone to know their HIV status, but they also don't want to use a condom. So it's a delicate balance, since hiding the infection can't be an excuse for irresponsible sexual conduct.

Despite everything, AIDS still causes suffering and death: if we don't see it that way, there will be no risk perception. Furthermore, AIDS is like all population health-dengue, clean water, garbage collection, chronic diseases. It is a problem of the whole society. The Ministries of Education, Culture, Tourism, everybody in and outside of government, has to work on this. If not, we are going to fail.

\section{MEDICC Review: And now your second book is about to be} published-AIDS: New Confessions to a Doctor.

Jorge Pérez: Yes. When I presented the first book, signing copies at the table, I saw a young girl walking back and forth. She finally came up to me. "You've written about my sister," she told me, and she even knew the page number. "She told me you treated her so well." Her sister had died by then, but she had left behind a newborn girl who was not infected. And there she was, too, the daughter, the spitting image of her mother. The little girl said her mother came down from heaven to talk to her. But her eyes were the saddest I had ever seen in my life-and they followed me.

So I decided to continue writing, this time about the families of my patients, the children being raised by their aunts and uncles, their grandparents. The sister of this child's mother gave me permission to use her letters to her newborn daughter in the second book. So I did. And this book is more about the Tropical Medicine Institute, the efforts by all our staff, and patients, too. It still has a personal touch, but I think it's more inclusive.

I hope at some other time I can write more optimistic stories: I hope many of our patients will live to see the cure for this terrible illness. That's my hope. That young people won't be threatened, will feel more secure. That the suffering will stop. Especially among the poor and other people who are most vulnerable-because it is the poor people around the world who are getting sick, and primarily those in richer countries who have treatment at hand.

MEDICC Review: What kind of challenges do you face as the new Director of the Tropical Medicine Institute?

Jorge Pérez: The first challenge is to step into the shoes of Gustavo Kourí, one of Cuba's great men of medical science, and to continue the research, teaching and medical services at the level he inspired.

Our priorities now are emerging and re-emerging infections, the new viruses, which are a challenge across the globe: $\mathrm{H} 1 \mathrm{~N} 1$ and its variations, avian flu, and others that will certainly appear. Then we have cholera in Haiti, so close to Cuba, with many of our doctors going back and forth-including from the Institute-so we have to be vigilant.

And then there is of course dengue, which we find throughout Latin America. The challenge is rapid case detection, but even more than that, vector control at the community level, which is the only way to really protect ourselves.

Another priority is to continue our collaboration with other developing countries in particular. And finally, we face a great challenge in increasing the visibility of our research results by publishing internationally.

\section{MEDICC Review: And will you continue to see patients?}

Jorge Pérez: The first call I got when I was named director came from a patient who wanted to know the same thing. I'll tell you what I told him: I didn't become a doctor to be a director; I became a doctor for my patients. So the Ministry of Public Health agreed that I should keep my medical practice. I have office hours once a week for about 46 weeks out of the year, and I see $20-30$ patients during each session. I don't intend to change that.

MEDICC Review: Returning to the most difficult days of the AIDS epidemic in Cuba-in the late 1980s and early 1990s when few drugs were available for patients and there was really little that could be done. Yet, you were close to so many of them. How did you avoid burnout?

Jorge Pérez: I studied medicine to help people, to struggle to reverse situations like the ones created by AIDS. You have to keep struggling. You have to ask: how can I do it better?

When some doctors were depressed, I had to pull them out of the wards. There were times when it was a victory just to have a patient live ten more days, then just another year. When we began to control the opportunistic infections, that's when we breathed easier. It was real progress, and we were finally encouraged.

As for me personally, I'm the son of a mother who was born poor in Marianao, Havana; my father drove bus route Number 4 most of his working life. I spent my $15^{\text {th }}$ birthday in the Sierra Maestra mountains in the literacy campaign-I taught five people to read and write, and also took my 12-year-old brother along with me.

My father died of a heart attack when I was 21, the same year I started medical school, and that meant I had to help my other brothers and sisters. So adversity was no stranger to me. At the same time, my father's example stayed with me, my mother's too- - their honesty and their values.

So when I began to study medicine, I felt proud to be able to do something, that I was given the chance to make a difference, to change things. That's what has always kept me going. -1 - 